Geoprocessamento na análise morfoestrutural da região entre Marília e Presidente Prudente (SP) Alethéa Ernandes Martins Sallun, Kenitiro Suguio

\title{
GEOPROCESSAMENTO NA ANÁLISE MORFOESTRUTURAL DA REGIÃO ENTRE MARÍLIA E PRESIDENTE PRUDENTE (SP)
}

\section{Geoprocessing in the morphostructural analysis of region between Marília and Presidente Prudente (SP)}

\author{
Dra. Alethéa Ernandes Martins Sallun \\ Instituto Geológico do Estado de São Paulo \\ São Paulo/SP - Brasil \\ alethea@igeologico.sp.gov.br \\ Dr. Kenitiro Suguio \\ Instituto de Geociências da Universidade de São Paulo \\ São Paulo/SP - Brasil \\ kenitirosuguio@hotmail.com
}

Artigo recebido para publicação em 07/09/2008 e aceito para publicação em 03/01/2009

RESUMO: $\quad$ Foram utilizadas técnicas de geoprocessamento para caracterização morfoestrutural da região entre Marília e Presidente Prudente (SP) para compreender melhor a distribuição e ocorrência de depósitos quaternários. Os dados foram obtidos por meio do cruzamento de levantamento de campo, topografia, produtos de sensoriamento remoto e de cartas temáticas, utilizando Sistema de Informação Geográfica (SIG). A partir dos dados morfométricos obtidos foram compartimentadas regiões com predomínio de processos de morfogênese e pedogênese, com depósitos coluviais bem desenvolvidos. As feições geomorfológicas apresentam correlação com as unidades litológicas, estruturas tectônicas e presença de coberturas coluviais. A espessura de depósitos coluviais controla mudanças de permeabilidade e porosidade, refletindo também na erosão diferencial na região. Os dados obtidos poderão fornecer subsidios para decisões futuras sobre a ocupação antrópica, uma vez que os depósitos sedimentares quaternários da região entre Marília e Presidente Prudente (SP) têm alta suscetibilidade à contaminações antrópicas de solo e água subterrânea e erosão.

Palavras-chaves: Geoprocessamento. Depósitos coluviais. Quaternário.

ABSTRACT: For a better understanding of the distribution and occurence of Quaternary deposits between Marilia and Presidente Prudente (São Paulo State) was done the morphostructural characterization by geoprocessing techniques. The data was obtained by crossing the field surveys, topography, remote sensing products and thematic maps using Geographic Information System (GIS).. The morphometric data enabled the reconnaissance of regional compartments dominated by morphogenetic and pedogenetic processes with well developed colluvial deposits. Geomorphological features exhibited good correlation with the lithological units, the tectonic structures and the presence of colluvial covers. The thicknesses of the colluvial deposits have a close relationship with the permeability and porosity changes that also control differencial erosion in the region. The obtained data will subsidize future decisions on 
anthropogenic occupations, because the quaternary deposits between Marilia and Preseidente Prudente (SP) exhibit high susceptibility for anthropogenic contaminations of soil and groundwater and erosion.

Keywords: Geoprocessing. Colluvial deposits. Quaternary.

\section{Introdução}

Para melhor compreender a distribuição e ocorrência de depósitos cenozóicos existentes no oeste paulista foram empregadas técnicas de geoprocessamento para caracterização morfoestrutural da região entre Marília e Presidente Prudente (SP) (Figura 1). Os depósitos cenozóicos da região testemunham importantes eventos geológicos, mas as descrições e interpretações disponíveis são muito vagas e/ou desencontradas e precisavam ser aperfeiçoadas com base em dados quantitativos, para melhor elucidar a história geológica da área de estudo, bem como para fornecer subsídios para enfrentamento de questões ligadas à suscetibilidade à erosão acelerada (Fig. 1).

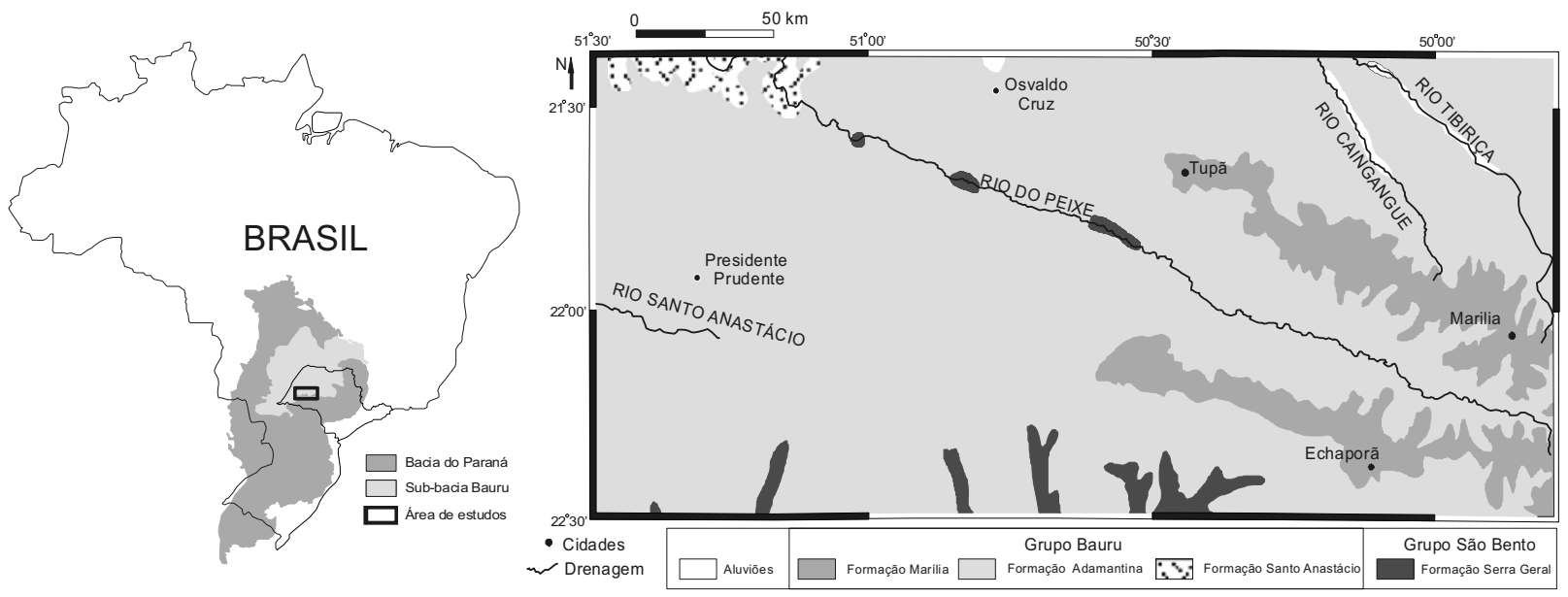

Figura 1. Situação geográfica da área de estudos e sua localização na Bacia do Paraná (modificado de ALMEIDA et al., 1981 e MILANI e RAMOS, 1998).

\section{Contexto Geológico}

Na região entre Marília e Presidente Prudente (SP) ocorrem rochas Mesozóicas da Bacia do Paraná (Grupo São Bento e Grupo Bauru) recobertas por depósitos cenozóicos (Fig. 1). O Grupo São Bento é representado pela Formação Serra Geral, que é formada por um conjunto de derrames de basaltos toleíticos de idade em torno de $132,4 \pm 1,1 \mathrm{Ma}$ (RENNE et al. 1992). A Sub-bacia Bauru (ARID, 1970; FÚLFARO et al., 1982, FERNANDES, 1992; COIMBRA e FERNANDES, 1994; FERNANDES e COIMBRA, 1996; FERNANDES, 1998) instalou-se sobre os derrames da Formação Serra Geral. Segundo Fernandes (1998) a Sub-bacia Bauru seria constituída por dois grupos parcialmente cronocorrelatos: Grupo Caiuá (formações Rio Paraná, Goio Erê e Santo Anastácio) e Grupo Bauru (formações Uberaba, Vale do Rio do Peixe, Araçatuba, São José do Rio Preto, Presidente Prudente e Marília, além dos analcimitos Taiúva). Como o objetivo deste estudo não é a litoestratigrafia do Grupo Bauru, e sim sua relação morfoestrutural com as coberturas cenozóicas e unidades de relevo, é utilizada a distribuição litológica de Almeida et al. (1981) para o Grupo Bauru: formações Marília, Adamantina, Santo Anastácio e Caiuá.

Sociedade \& Natureza, Uberlândia, 21 (1): 85-96, ABR. 2009 
Os depósitos cenozóicos são representados por colúvios, paleossolos e linhas-de-pedra (stone lines) que formam um depósito detrítico de 1,50 a 10 $m$ de espessura (PENTEADO e RANZANI, 1973; QUEIROZ NETO et al., 1977; MELO e PONÇANO, 1983; CARVALHO, 1976; LEPSCH, 1977). Ponçado et al. (1981) descreveram depósitos coluviais associados a relevos suaves que refletiriam granulometria e composição mineralógica correlacionáveis às rochas basais. Seriam depósitos arenosos de alta permeabilidade e porosidade, que conteriam fragmentos centimétricos dispersos de restos vegetais carbonizados, e apresentariam em média $8 \mathrm{~m}$ de espessura, exibindo na base linha-depedra limonitizada e/ou constituída de fragmentos de canga. Segundo Fúlfaro e Suguio (1974) os depósitos são mal estruturados e confundidos com elúvios, pois pouco se diferenciariam do material de alteração das rochas regionais, denotando sempre pequeno transporte.

$\mathrm{Na}$ área de estudos, Sallun (2006) agrupou os depósitos cenozóicos em coluviais e aluviais segundo critérios sedimentológicos, morfológicos e genéticos. Os depósitos coluviais são caracterizados pela predominância de areia e areia argilosa com alta maturidade mineralógica, sendo que os depósitos mais espessos são caracterizados pela predominância de areia fina. Recentemente, Sallun et al. (2007) denominou de Aloformação Paranavaí os depósitos coluviais quaternários que ocorrem na Bacia Hidrográfica do Alto Rio Paraná. Datações por luminescência forneceram idade pleistocênica para os depósitos coluviais $(9.000 \pm 1.000 \quad$ a $980.000 \pm 100.000$ anos A.P.) e aluviais ( $14.000 \pm 2.000$ a $240.000 \pm 30.000$ anos A.P.). Esses depósitos achamse instalados sobre quatro superfícies peneplanizadas afeiçoadas no Quaternário: I (1.000.000 a 400.000 anos A.P.), II (400.000 a 120.000 anos A.P.), III (120.000 a 10.000 anos A.P.) e IV (10.000 anos A.P. até hoje).

Riccomini (1995) teria reconhecido evidências diretas de neotectonismo no Platô de Marília, onde linhas-de-pedra superpostas à Formação Adamantina estariam seccionadas por falhas normais com rejeito decimétrico, que sugeririam extensão na direção WNW.

\section{Materiais e Métodos}

Foi realizada uma análise geomorfológica de âmbito regional que buscou a caracterização morfoestrutural e identificação dos depósitos cenozóicos, correlacionando-os a níveis geomorfológicos. A classificação dos terrenos se baseou na definição e identificação de áreas homogêneas. Foram empregadas técnicas de geoprocessamento e observações em trabalhos de campo, utilizando produtos de sensoriamento remoto e geradas cartas temáticas através do Sistema de Informação Geográfica (SIG).

Os documentos cartográficos foram compilados e digitalizados. Para a obtenção dos dados de sensoriamento remoto, foram utilizados recortes georreferenciados de quatro imagens multiespectrais do sensor ETM+ do satélite LANDSAT-7. As imagens possuem órbita e ponto: 221/75 e 222/75 (obtidas em 05/08/2001); 221/76 e 222/76 (obtidas em 12/08/ 2001). As bandas utilizadas são: ETM+1, 2, 3, 4, 5 , 6, 7 e 8 do sensor ETM+, sendo que a banda ETM+8 pancromática ( $15 \times 15$ m de resolução) no visível e infravermelho próximo e a ETM +6 no infravermelho termal, enquanto as outras bandas apresentam resolução de 30 x $30 \mathrm{~m}$. Foi realizada a fusão de todas as bandas que aumentou a resolução espacial $(15 \mathrm{x}$ $15 \mathrm{~m})$ com preservação das propriedades radiométricas. Para a composição das bandas foi utilizado o denominado "High Pass Filter Method" (CHAVEZ JR. et al., 1991), com aplicação de filtros passa-alta (CRÓSTA, 1993), e análise por componentes principais (PC1) para realce da informação textural.

Foram gerados os seguintes mapas:

1) Modelo digital de terreno (MDT): foi gerado a partir da base topográfica digitalizada com espaçamento de pontos de $100 \mathrm{~m}$, na folha topográfica na escala 1:50.000. Para cada ponto obtido na digitalização foi atribuído o valor de elevação em 
metros. Para a confecção do modelo foi utilizado o método "triangular irregular network" (TIN) (PEUKER et al., 1978) utilizando todos os pontos obtidos, que segundo Burrough e McDonnell (2000) apresenta melhores resultados do que a utilização de grades regulares para a confecção de MDT, utilizados para o cálculo de hipsometria, declividade e direção da declividade de encostas.

2) Mapa hipsométrico: foi confeccionado com base no MDT em classes altimétricas com espaçamento de $20 \mathrm{~m}$, de acordo com a resolução do mapa topográfico original em escala 1: 50.000. O mapa hipsométrico destaca a distribuição e organização espacial das principais unidades de relevo, e representa a altura da área de estudo em relação ao do nível do mar.

3) Mapa de declividade das encostas: o grau de declividade representa em geral blocos de igual intensidade de dissecação fluvial, e reflete a taxa de variação na elevação. O mapa foi confeccionado a partir do MDT com os valores de declividade em graus. Os intervalos de classes de declividade utilizados são consagrados em estudos de processos erosivos (GUERRA e CUNHA, 1996).

4) Mapa de orientação das encostas: indica a direção dos declives das encostas, gerado a partir do MDT, com os valores de orientação em azimute.

5) Mapa de rugosidade: foi confeccionado com base no MDT. Foi estabelecida uma malha quadrática com células de $500 \times 500 \mathrm{~m}$ e em cada célula foi calculada a razão entre a área real e a área plana (HOBSON, 1972).

6) Mapa de densidade de drenagem: a drenagem das folhas topográficas foi digitalizada com espaçamento de pontos de $100 \mathrm{~m}$. Foi estabelecida uma malha quadrática com células de $500 \times 500 \mathrm{~m}$ para a área de estudos, em que o parâmetro de densidade de cada célula foi obtido a partir do número de pontos que cada célula continha (Fig. 2).
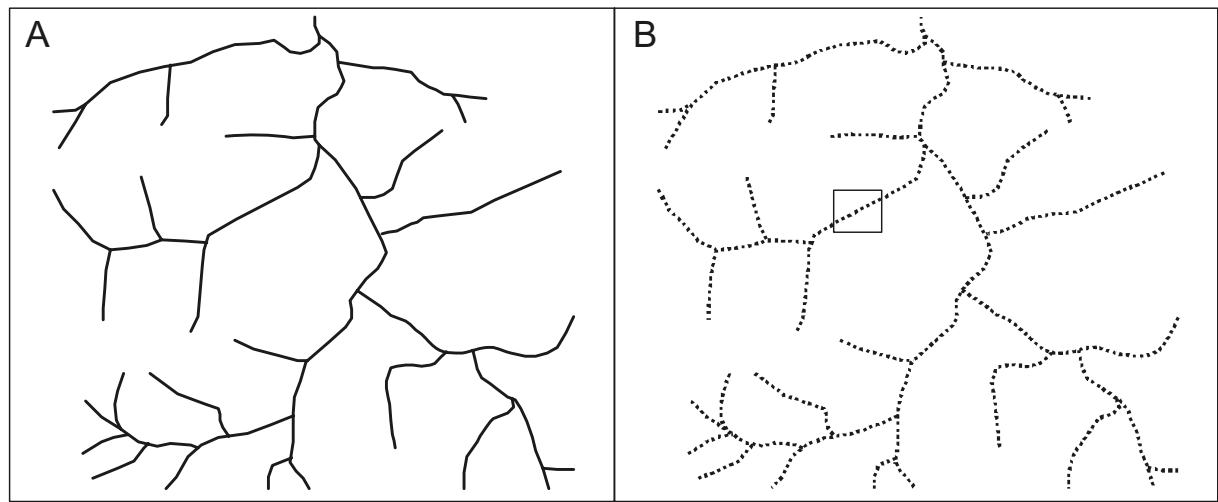

Célula de 500 x $500 \mathrm{~m}$

Figura 2. Exemplo de uma drenagem de folha topográfica (escala 1: 50.000) (A) e os pontos utilizados para a digitalização dessa drenagem para a confecção do mapa de densidade de drenagem (B).

\section{Resultados}

A caracterização morfoestrutural foi fundamentalmente baseada nos comportamentos da rede de drenagem e nos aspectos texturais, tendo como base o mapeamento geomorfológico realizado por
Ponçano et al. (1981) e superfícies definidas por Sallun (2003). Através das composições realizadas nas imagens de satélite foi possível reconhecer os limites das unidades geomorfológicas definidas pelos autores (Fig. 3). 


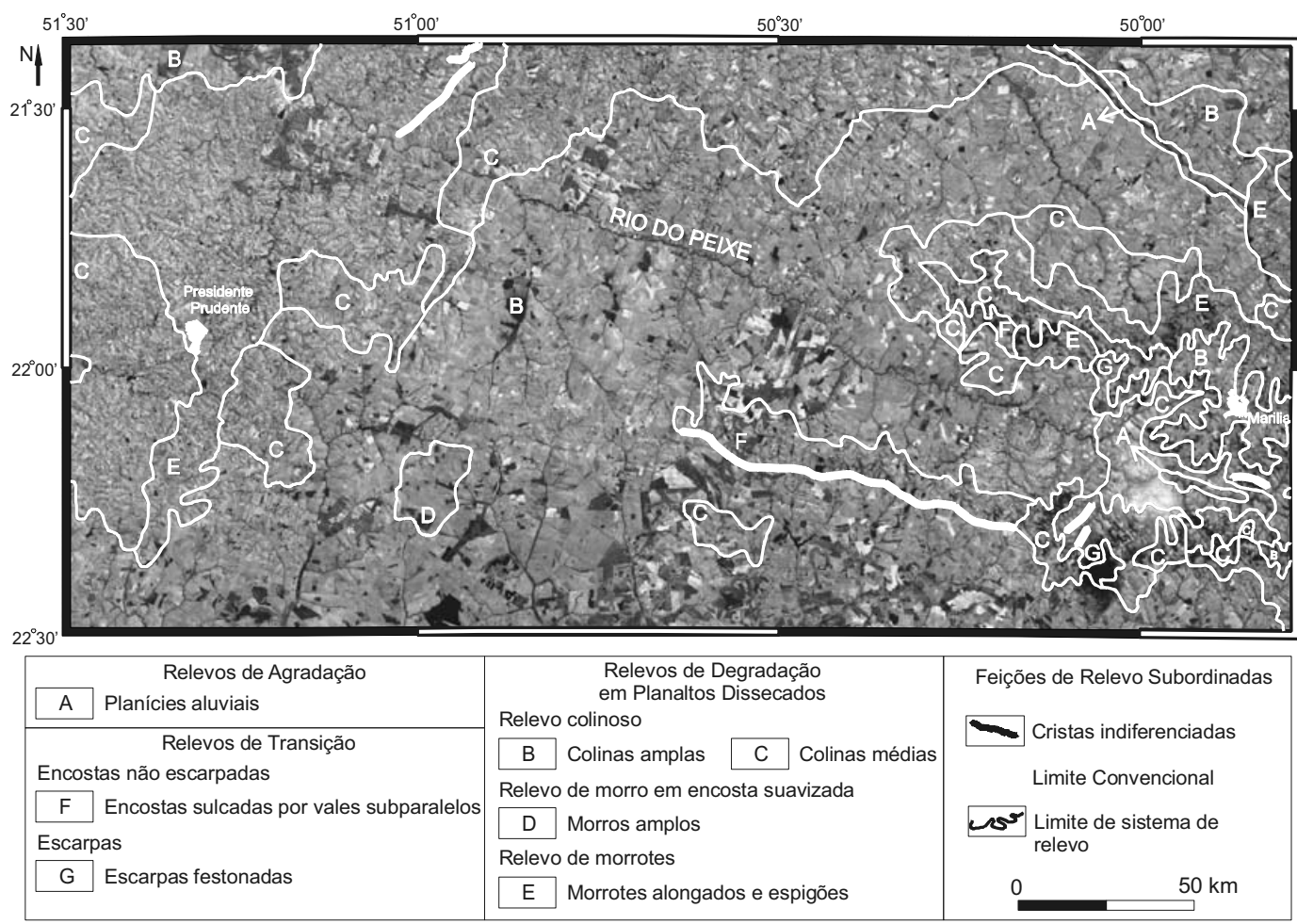

Figura 3. Composição PC1 (componentes principais) da imagem de satélite LANDSAT-7 da área de estudo. Pode-se observar que na região da cidade de Marília ocorrem relevos cuestiformes, devido à ocorrência de rochas da Formação Marília, com alta densidade de drenagem associada às escarpas festonadas e morrotes alongados e espigões e onde a cobertura quaternária é mais espessa a densidade de drenagem é baixa. Notar o vale retilíneo do Rio do Peixe (unidades de relevo de PONÇANO et al., 1981).

\subsection{Hipsometria}

O mapa hipsométrico (Fig. 4) mostrou-se adequado ao tipo de compartimentação proposto e demonstra o controle efetivo das unidades geológicas e estruturas tectônicas presentes. No contexto regional verifica-se a compartimentação do relevo em quatro superfícies distintas, formando patamares escalonados de SE para NW (Fig. 5), delimitadas por zonas de maior declividade, correspondendo ao alinhamento de elementos e unidades geomorfológicas, como escarpas proeminentes, cristas e vales lineares. Essa feição geomorfológica é caracterizada por extensas superfícies de baixa declividade, que foram preservadas como divisores de águas, e em geral exibem correspondência com os mapas hipsométrico e geomorfológico. 
Geoprocessamento na análise morfoestrutural da região entre Marília e Presidente Prudente (SP)
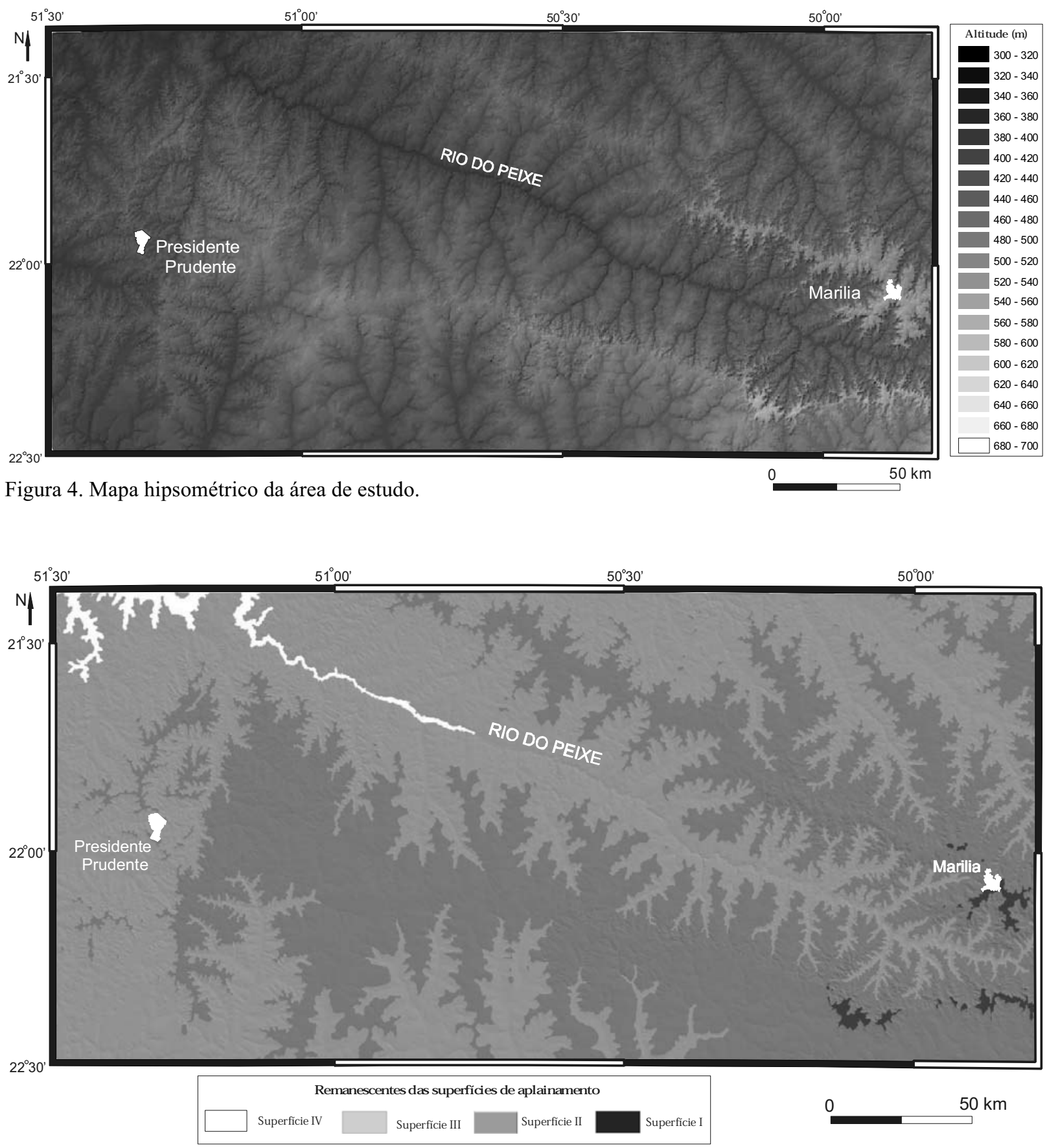

Figura 5. Mapa dos remanescentes das superfícies de aplainamento identificadas.

Ocupando uma pequena área, a classe altimétrica mais baixa $(300-320 \mathrm{~m})$ representa o preenchimento do vale do Rio do Peixe por depósitos aluviais atuais. Essa classe altimétrica define uma superfície de aplainamento, denominada IV, a mais nova. Delimitando as regiões de forma alongada que ocorrem adjacentes ao Planalto de Marília têm-se colinas amplas, que exibem topo aplainado (320 $460 \mathrm{~m}$ ) e textura lisa, com transição gradativa para classes altimétricas mais baixas e acréscimo para mais altas, em parte associadas ao afloramento de rochas resistentes da Formação Marília, em que o padrão 
meandrante do Rio do Peixe torna-se retilíneo, na direção NW-SE. Dessa forma, o Rio do Peixe provavelmente está encaixado em uma estrutura tectônica maior que também controla a forma de dissecação do Planalto de Marília, com morrostestemunho que exibem direção NW-SE, não tendo ainda alcançado um perfil de equilíbrio nessa porção. Nesta superfície, denominada III, ocorrem depósitos coluviais espessos e bem desenvolvidos associados à dissecação dos principais afluentes dos rios do Peixe, Paranapanema e Aguapeí.

Morrotes, colinas médias e colinas amplas $(460-600 \mathrm{~m})$ estão associados à superfície de aplainamento II, onde ocorrem depósitos coluviais espessos e bem desenvolvidos. Essa classe altimétrica decresce transicionalmente de regiões mais altas para mais baixas, e as curvas de nível dessa classe são menos espaçadas nos limites com a superfície I. A textura dessa superfície de aplainamento, na área de ocorrência de morrotes e colinas médias, exibe uma rugosidade maior, destacando-se perante as texturas das outras unidades geomorfológicas, provavelmente associada à geração de depósitos cenozóicos diferentes dos identificados em outras superfícies de aplainamento.

Ocupando uma pequena área, a classe altimétrica mais alta $(600-700 \mathrm{~m})$ representa o Planalto de Marília que se eleva a partir dos vales dos rios do Peixe, Aguapeí e Paranapanema até altitude de $713 \mathrm{~m}$, com limites bem retilíneos na borda sul e recortados na parte norte. No quadro geral, esse planalto apresenta-se recortado pela ação destrutiva da drenagem, que atua na dissecação do mesmo. As principais drenagens exibem controle estrutural com vales retilíneos de direção N-S e NE-SW para canais de $1^{\circ}, 2^{\circ}$ e $3^{\circ}$ ordem e NW-SE para canais de $4^{\circ}$ ordem ou mais. No topo deste planalto, ocorre a superfície de aplainamento I que exibe as mesmas características da superfície de aplainamento II, textura lisa associada a colinas amplas, em altitudes bem maiores associadas a depósitos coluviais bem desenvolvidos.

\subsection{Declividade}

As maiores declividades ocorrem nos limites do Planalto de Marília, associados aos morrotes alongados e espigões, escarpas festonadas e colinas médias. Na porção superior do Planalto de Marília a declividade é muito menor, e pode ser observada a superfície de aplainamento I. As maiores declividades (maior que $30^{\circ}$ ) estão associadas com a ocorrência dos vales das principais drenagens, e com a escarpa do Planalto de Marília. Os vales formam rampas junto à escarpa do Planalto de Marília, e geralmente apresentam-se recobertos por colúvios. Na região do Planalto de Marília, as maiores declividades estão associadas somente ao lado norte onde se desenvolve a bacia do Rio do Peixe, sendo que o lado sul exibe uma declividade bem menor onde se desenvolve a bacia do Rio Paranapanema.

Na região de Presidente Prudente, porção oeste da área de estudo, a declividade exibe valores intermediários na área de ocorrência de morrotes alongados e espigões e colinas médias que são associados a menor espessura de depósitos coluviais, e a superfície de aplainamento III. Regiões com declividade menor que $5^{\circ}$ ocupam a maior parte da área, associada à superfície de aplainamento II e a colinas amplas associadas a depósitos coluviais mais espessos (Fig. 6).

O vale do Rio do Peixe é bem delimitado por zonas de maior declividade, demonstrando entalhamento vertical em suas bordas e forma retilínea na direção NW-SE, e a simetria de direção preferencial N-S e NNE-SSW que os rios distributários exibem. Na porção mais baixa do vale do Rio do Peixe, as declividades diminuem drasticamente em uma região mais plana, associada a superfície de aplainamento IV. 


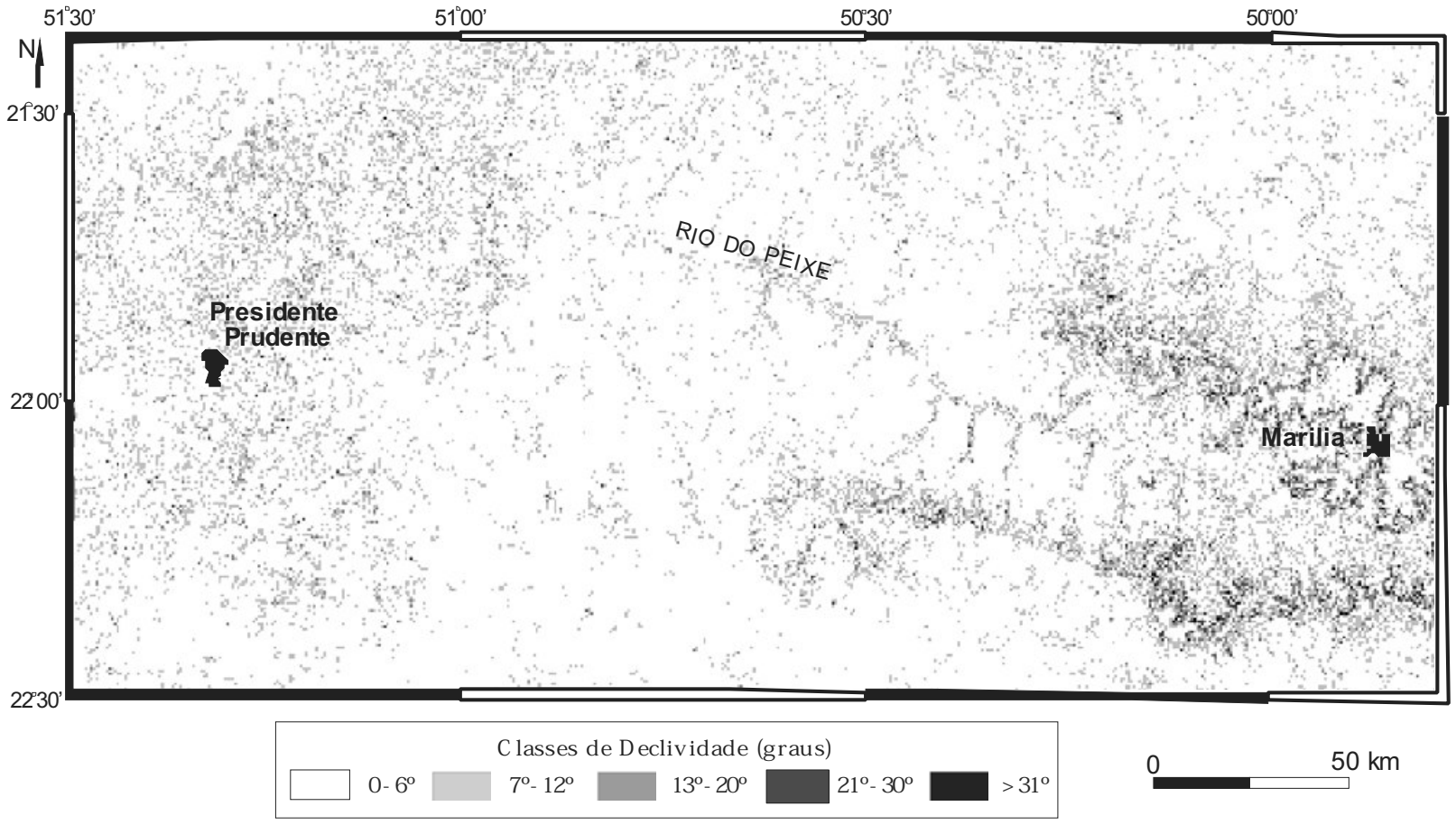

Figura 6. Mapa de declividade da área de estudo.

\subsection{Orientações de vertentes}

A orientação de vertentes (Fig. 7) pode compartimentar duas regiões com características diferentes:

1) ocorrência de maior espessura dos depósitos coluviais: encostas apresentam maior tamanho em área, com direções diferentes, associadas à menor declividade. Esta região está associada com colinas amplas e a superfície de aplainamento II. Provavelmente as vertentes assumem este comportamento homogêneo devido à presença de depósitos coluviais espessos e bem desenvolvidos que ocorrem nesta região.

2) extremo oeste e leste da área de estudo: as encostas apresentam menor tamanho em área e tem diversas direções. Estas regiões estão associadas com a superfície de aplainamento III, que exibe maiores declividades, associados a depósitos coluviais menos desenvolvidos, com menor espessura e expressão morfológica.

\subsection{Densidade de drenagem}

A densidade de drenagem (Fig. 8) denota anomalias de baixa e alta densidade de drenagem subdividindo a área de estudo em quatro blocos:

1) Planalto de Marília: exibe a zona de maiores densidades de drenagem da área de estudo (13 e 46 pontos por célula), com porções de máximo associadas a escarpas festonadas e morrotes alongados e espigões;

2) região de ocorrência de maior espessura dos depósitos coluviais: zona de baixa densidade de drenagem em colinas amplas ( 0 a 13 pontos por célula), associadas à maior porção da superfície de aplainamento II. Provavelmente está associada com regiões que apresentam maior porosidade.

3) região oeste e noroeste da área de estudo: exibe alta densidade, mas com valores mais baixos que a região do Planalto de Marília (13 a 39 pontos por célula), associados a colinas médias e morrotes alongados e espigões delimitados por estruturas N-S

Sociedade \& Natureza, Uberlândia, 21 (1): 85-96, ABR. 2009 
e NE-SW, associados à superfície de aplainamento III.
Rio do Peixe: exibe baixa densidade (0 a 7 pontos por célula) e está associada à superfície de aplainamento IV, em região de extensos terraços atuais.
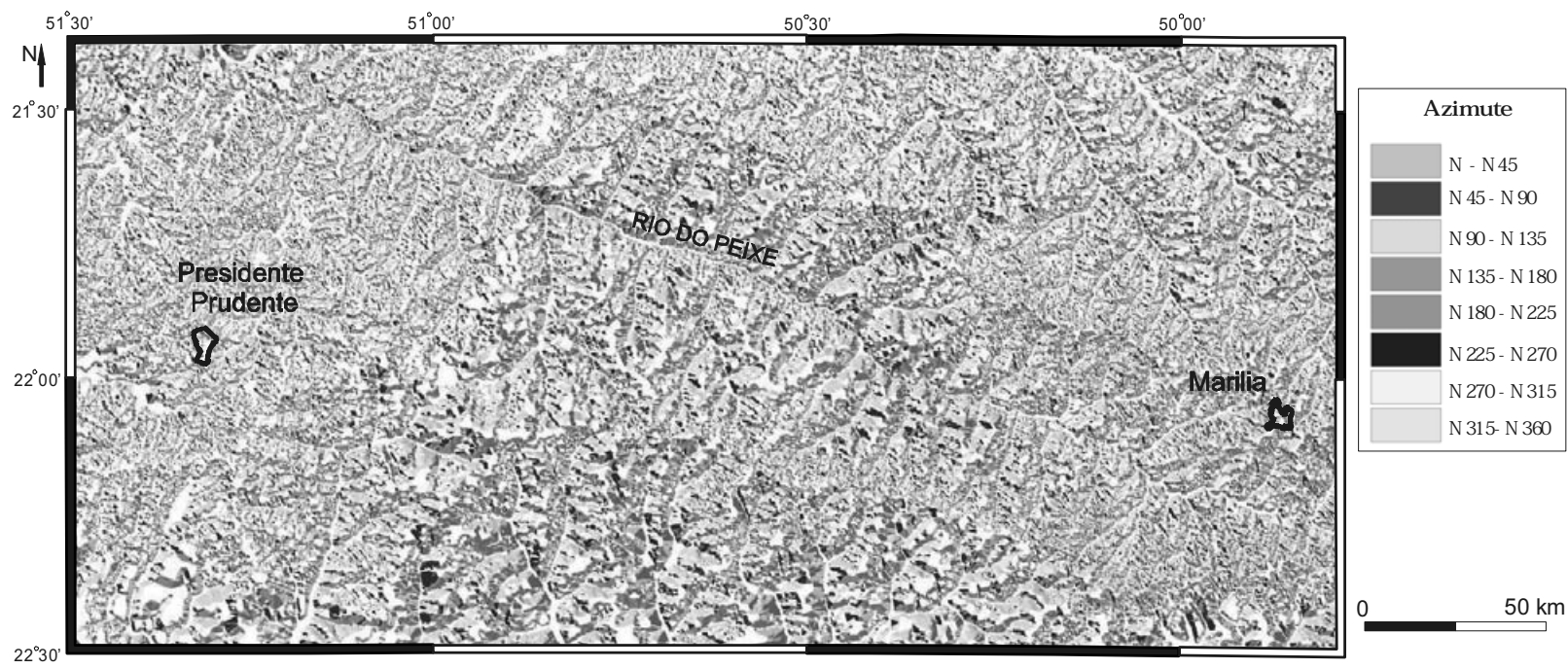

Figura 7. Mapa de orientação de vertentes.
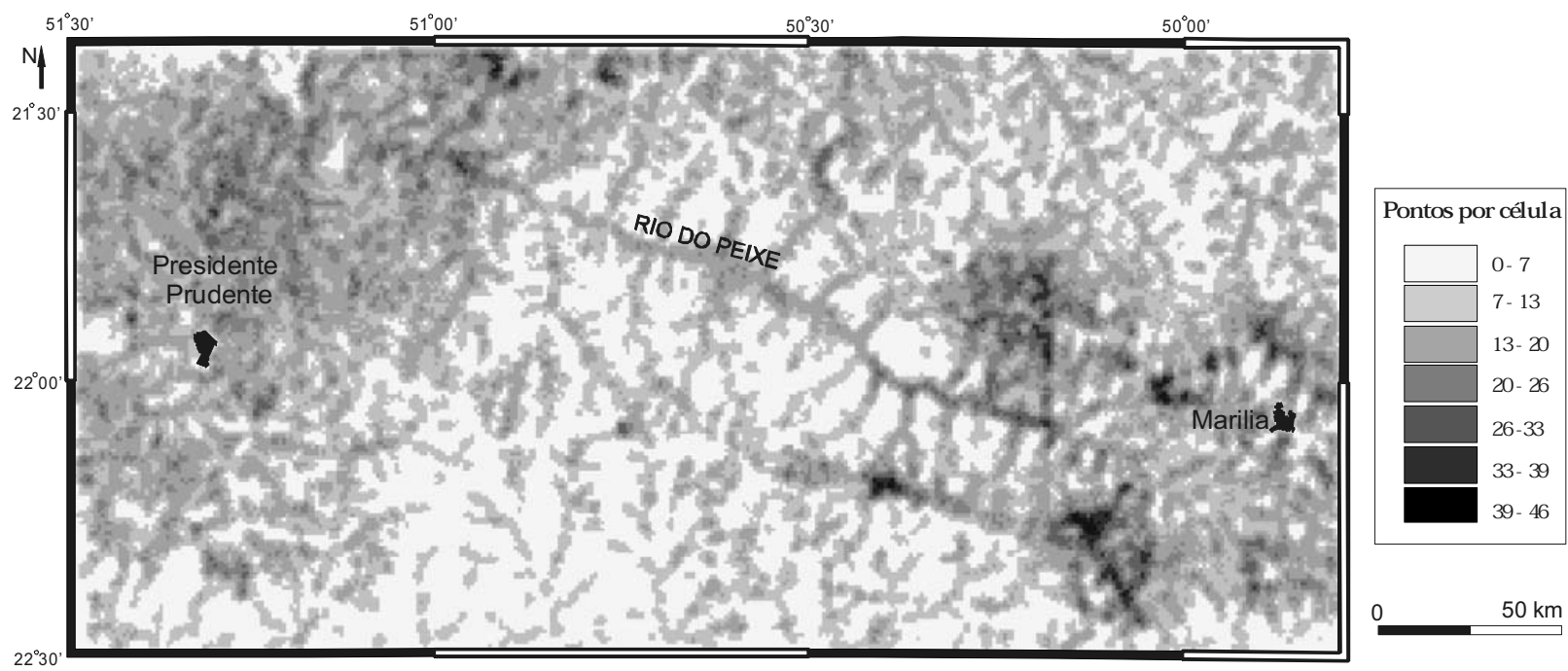

Figura 8. Mapa de densidade de drenagem.

\subsection{Rugosidade do relevo}

A região apresenta, em maior parte, baixos valores de rugosidade, entre 1 e 1,0048. As porções de maior rugosidade estão associadas aos limites das superfícies de aplainamento II e I e do Planalto de
Marília (1,0048 a 1,0298).

Em geral as superfícies de aplainamento I, II e IV (1 a 1,0033) exibem menor rugosidade do que a superfície de aplainamento III (1 a 1,01). A expressão morfológica da presença de depósitos coluviais bem 
desenvolvidos nas superfícies I e II pode ser verificada como rugosidade baixa em relação a outras regiões, sempre associados a área de ocorrência de colinas amplas. Pode-se notar que as regiões com baixa densidade de drenagem (Fig. 8) sempre estão associadas a áreas de menor rugosidade (Fig. 9).
Na região de Presidente Prudente, porção oeste da área de estudo, a rugosidade exibe valores intermediários associados a morrotes alongados e espigões. Essa rugosidade pode ser muito bem observada na Fig. 3, e está associada a superfície de aplainamento III.

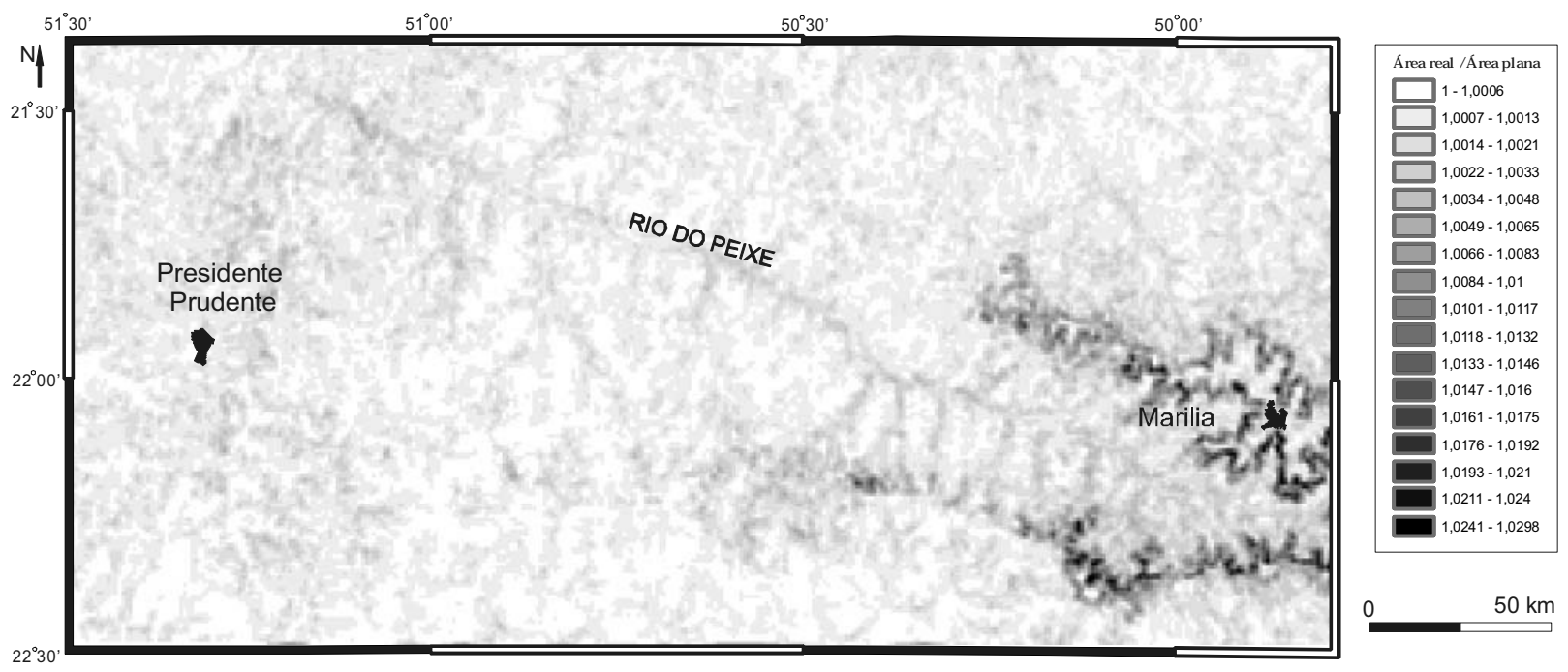

Figura 9. Mapa de rugosidade do relevo

\section{Conclusões}

A partir da análise dos dados morfométricos podem ser observadas na área de estudo, regiões com o predomínio dos processos de morfogênese e de pedogênese, com depósitos coluviais bem desenvolvidos. As feições geomorfológicas estão relacionadas ao comportamento do escoamento superficial por diferenças litológicas e de direções preferenciais de lineamentos. A ocorrência de diferentes unidades do Grupo Bauru, da Formação Serra Geral, espessas coberturas coluviais e estruturas tectônicas presentes nas unidades, são responsáveis pela variação e compartimentação do relevo em escala regional. As camadas sedimentares da Formação Marília deram origem a relevos cuestiformes devidos a rochas mais resistentes, com morrotes-testemunho e espigões alongados de direção E-W.

Toda a área é coberta por uma rede de drenagem organizada, em geral dendrítica, notandose um controle estrutural ligado a juntas tectônicas e a corpos litológicos mais resistentes ao intemperismo e erosão, sendo que alguns canais principais estão estabelecidos em lineamentos estruturais pelos padrões de vale retilíneos. Os rios do Peixe e Aguapeí adotam padrão meandrante em vale encaixado, e juntamente com os afluentes, esses rios assumem padrão subdendrítico. Onde a cobertura cenozóica é mais espessa, porosa e permeável, a densidade da drenagem é mais baixa, porque deve predominar o processo de infiltração de águas pluviais.

De forma geral podemos apontar aspectos importantes detectados através das análises geomorfológicas regionais e tectônica que dizem respeito aos depósitos cenozóicos:

- feições de colinas amplas que ocupam a maior porção da área de estudo, estão associadas à maior espessura de depósitos coluviais. A composição granulométrica desses depósitos que ocorrem nas colinas amplas é diferente dos depósitos que ocorrem sobre as outras unidades geomorfológicas: 
apresentam menor porcentagem da distribuição fina (silte e argila) e maior porcentagem de areia fina. Essa composição diferente deve mudar algumas propriedades físicas, como permeabilidade e porosidade, refletindo na geomorfologia da região por erosão diferencial;

- nas regiões onde a espessura de depósitos coluviais é menor, a expressão morfológica é diferente exibindo textura relacionada às rochas do Grupo Bauru e às estruturas tectônicas presentes.

Dessa forma, pode-se observar que ocorreram vários ciclos de deposição dos sedimentos durante a formação das superfícies de aplainamento e que essas superfícies continuaram a serem moldadas concomitantemente ao longo do tempo.

\section{Agradecimentos}

O projeto foi desenvolvido com o apoio dos auxílios à pesquisa do CNPq (Processo 47404/20019 NV) e FAPESP (Processo 01/07469-7), bolsa de mestrado FAPESP à Alethéa E. M. Sallun (Processo 00/10672-6) e bolsa de produtividade em pesquisa CNPq ao Kenitiro Suguio (Processo 304718/2003-3).

\section{Referências}

ALMEIDA, F.F.M. de. et al. Mapa Geológico do Estado de São Paulo (escala 1:500.000). São Paulo: Instituto de Pesquisas Tecnológicas, 1981. 126p.

ARID, F.M.A. Formação Bauru na região norteocidental do Estado de São Paulo. In: CONGRESSO BRASILEIRO DE GEOLOGIA, 24, 1970, Brasília. Resumos das Conferências e Comunicações, Brasília: SBG, 1970. p. 373-377.

BURROUGH, P.A.; McDONNELL, R.A. Principles of geographical information systems. New York: Oxford University, 2000. 333p.

CARVALHO, A. Solos da região de Marília. Relações entre a pedogênese e a evolução do relevo. São Paulo, 1976. 163p. Tese (Doutorado em Geografia Física),
Faculdade de Filosofia, Ciências e Letras, Universidade de São Paulo, 1976.

CHAVEZ JR., P.S.; SIDES, S.C.; ANDERSON, J.A. Comparison of three different methods to merge multiresolution and multispectral data: Landsat TM and SPOT Panchromatic. Photogrammetric Engineering \& Remote Sensing, Bethesda, vol. 57, n. 3, p. 295-303, 1991.

CRÓSTA, A.P. Processamento digital de imagens de sensoriamento remoto. Campinas: UNICAMP, 1993. $170 \mathrm{p}$.

COIMBRA, A.M.; FERNANDES, L.A. A paleogeografia da Bacia Bauru (Cretáceo Superior, Brasil). In: Congreso Argentino Paleontología y Bioestratigrafia, 6, 1994, Trelew, Actas, Trelew: AGA, 1994. p. 85-90.

FERNANDES, L.A. A cobertura cretácica suprabasáltica no Paraná e Pontal do Paranapanema (SP): os grupos Bauru e Caiuá. São Paulo, 1992. 129p. Dissertação (Mestrado em Geologia Sedimentar), Instituto de Geociências, Universidade de São Paulo, 1992.

FERNANDES, L.A.; COIMBRA, A.M. A. Bacia Bauru (Cretáceo Superior, Brasil). Anais da Academia Brasileira de Ciências, Rio de Janeiro, 68, p. 195205, 1996.

FERNANDES, L.A. Estratigrafia e evolução geológica da parte oriental da Bacia Bauru (Ks, Brasil). São Paulo, 1998. 232p. Tese (Doutorado em Geologia Sedimentar), Instituto de Geociências, Universidade de São Paulo, São Paulo, 232p., 1998.

FÚLFARO, V.J. et al.. Compartimentação e evolução tectônica da Bacia do Paraná. Revista Brasileira de Geociências, São Paulo, 12, 590-611, 1982.

FÚLFARO, V.J.; SUGUIO, K. O cenozóico paulista: gênese e idade. In:, CONGRESSO BRASILEIRO DE GEOLOGIA, 28, 1978, Porto Alegre. Anais, Porto Alegre: SBG, 1978, vol. 3, p. 91-102. 
GUERRA, A.J.T.; CUNHA, S.B. da. Geomorfologia e meio ambiente. Rio de Janeiro: Bertrand Brasil, 1996. 394.

HOBSON, R.D. Surface roughness in topography: quantitative approach. In: CHORLEY, R.J. (ed.) Spatial analysis in geomorphology. New York: Harper \& Row, 1972. p. 222-245.

LEPSCH, I.F. Superfícies geomorfológicas e depósitos cenozóicos em Echaporã, SP. Boletim Paulista de Geografia, São Paulo, vol. 53. p. 5-34, 1977.

MELO, M.S. de; PONÇANO, W.L. Gênese, distribuição e estratigrafia dos depósitos cenozóicos no Estado de São Paulo. São Paulo: Instituto de Pesquisas Tecnológicas, 1983. 75p. (Série Monografias, 1394).

MILANI, E.J.; RAMOS, V.A. Orogenias paleozóicas do domínio sul-oriental do Gondwana e os ciclos de subsidência da Bacia do Paraná. Revista Brasileira de Geociências, São Paulo, vol. 28, n. 4, p. 473-484, 1998.

PENTEADO, M.M.; RANZANI, G. Problemas geomorfológicos relacionados à gênese dos solos podzolizados, Marília. Sedimentologia e Pedologia, São Paulo, vol. 6, p. 1-23, 1973.

PEUKER, T.K. et al. In: AMERICAN CONGRESS ON SURVEY AND MAPPING-DTM SYMPOSIUM, 5, 1978, St. Louis, Proceedings, St. Louis: USGS, 1978, p. 24-31.

PONÇANO, W.L. et al. Mapa Geomorfológico do Estado de São Paulo (escala 1:500.000). São Paulo: Instituto de Pesquisas Tecnológicas, 1981. 94p.

QUEIROZ NETO, J.P. et al. Formações superficiais da região de Marília, SP. Sedimentologia e Pedologia, São Paulo, vol. 31, p. 1-28, 1977.
RENNE, P. et al. The age of Paraná Flood Volcanism, rifting of Gondwanaland, and the Jurassic-Cretaceous boundary. Science, Washington, vol. 258, p. 975-979, 1992.

RICCOMINI, C. Arcabouço estrutural e aspectos do tectonismo gerador e deformador da bacia Bauru no estado de São Paulo. Revista Brasileira de Geociências, São Paulo, vol. 27, n. 2, p. 153-162, 1997.

SALLUN, A. E. M. Depósitos cenozóicos da região entre Marília e Presidente Prudente (SP). São Paulo, 2003. 171p. Dissertação (Mestrado em Geologia Sedimentar), Instituto de Geociências, Universidade de São Paulo, 2003.

SAllun, A. E. M.; SUGUiO, K. Depósitos quaternários da região entre Marília e Presidente Prudente (SP). Revista Brasileira de Geociências, São Paulo, vol. 36, p.385-395, 2006.

SALLUN, A. E. M.; SUGUIO, K.; STEVAUX, J. C. Proposição formal do Alogrupo Alto Rio Paraná (SP, PR e MS). Geologia USP - Série Científica, São Paulo, vol. 7, p. 49-70, 2007. 